\title{
A IMPLANTAÇÃO E A CONSOLIDAÇÃO DA INDÚSTRIA DE CONFECÇÃO NA MESOREGION SUDOESTE DO PARANÁ
}

\section{The implantation and the consolidation of the industry of con- fection in the southwestern mesoregion of the Paraná}

\author{
Sonia Mar dos Santos MIGLIORINI ${ }^{1}$
}

\begin{abstract}
RESUMO
A indústria de confecção foi uma das indústrias precursoras do processo de industrialização da Mesoregion Sudoeste do Paraná. Essa indústria iniciou suas atividades na Mesoregion no final da década de 1970 e início da década de 1980. A partir da década de 1990, teve um expressivo crescimento tanto em número de unidades industriais quanto em termos de participação na geração de emprego e renda, posicionando-se entre os setores industriais com maior importância econômica para a região. O presente artigo tem por objetivo identificar os fatores que condicionaram a implantação da indústria de confecção na Mesoregion Sudoeste do Paraná e suas perspectivas. Como conclusão, apresenta um conjunto de fatores que influenciaram na implantação e consolidação da indústria de confecção na Mesoregion e avalia as perspectivas dessa indústria regional com base no estudo de suas vantagens competitivas.
\end{abstract}

Palavras-chave:

Indústria de confecção; vantagens competitivas; Região Sudoeste.

\begin{abstract}
The confection industry was one of the precursory industries of the process of industrialization of Southwestern Mesoregion of Paraná. This industry began its activities in Mesoregion in the end of the 1970's and beginning of the 1980's. Starting from the 1990's, the number of industrial units have grown immensely in terms of increase of jobs and income, being part of the industrial sectors with larger economical importance of the region. The present article aims at identifying the factors that conditioned the implantation of the confection industry in Southwest Mesoregion of Paraná and their perspectives. In conclusion, it presents a group of factors that have influenced the implantation and consolidation of the confection industry in Mesoregion and it evaluates the perspectives of that regional industry based upon in the study of their competitive advantages.
\end{abstract}

\section{Key words:}

Confection industry; competitive advantages; Southwestern Region. 
MIGLIORINI, S. M. S. A implantação e a consolidação da indústria de confecção...

\section{INTRODUÇÃO}

A indústria de confecção, por exigir pouco nível tecnológico e pequeno investimento de capital, é um dos setores que mais cedo se desenvolveu no País e, por conta dessa característica, em muitas regiões, assim como ocorreu no início da industrialização do Brasil, essa indústria é a precursora do processo de industrialização. Nesse contexto está a Mesoregion Sudoeste do Paraná, área de estudo desta pesquisa, onde a indústria de confecção foi uma das primeiras a se desenvolver e tornou-se um dos setores mais importantes para o desenvolvimento econômico da Região.

A partir de 1977, foram implantadas as primeiras indústrias de confecção na Mesoregion Sudoeste, oriundas da transformação dos chamados alfaiates em unidades industriais, surgindo primeiramente em dois municípios da Mesoregion (Ampére e Francisco Beltrão) e espalhando-se pela maioria dos municípios da região; no final dos anos de 1980 e no decorrer da década de 1990, tornou-se um dos setores industriais com maior importância econômica da região, em termos de geração de emprego e renda. Nos últimos anos, especialmente a partir da década de 1990, a indústria de confecção regional vem crescendo aceleradamente tanto em número de unidades industriais, com um crescimento de $304 \%$ entre 1990 e 2006, quanto em escala de produção e comercialização.

Este artigo tem como objetivo principal analisar os condicionantes da implantação da indústria de confecção da Mesoregion Sudoeste do Paraná após 1970 e suas perspectivas. Para tanto, buscou-se identificar os mercados atingidos por essa indústria e as suas fontes de vantagens comparativas em escala nacional e regional bem como a importância atual da indústria de confecção no desenvolvimento da Mesoregion e suas perspectivas para os próximos anos. O artigo está estruturado em cinco seções, além desta introdução. $\mathrm{Na}$ primeira realizou-se uma análise sobre a metodologia utilizada nos estudos da competitividade sistêmica, seus conceitos e modelos, com o propósito de destacar os fatores sistêmicos que influenciam a competitividade das empresas que operam na indústria têxtil, bem como os fatores que influenciam a escolha do local para a implantação dessa indústria, especialmente da indústria de confecção. A competitividade da indústria de confecção, especificamente, foi abordada na segunda seção, que tem como base os modelos apresentados na seção primeira. Já na terceira seção, realizou-se uma abordagem sobre a implantação e desenvolvimento da indústria de confecção na Mesoregion Sudoeste do Paraná, com o objetivo de resgatar a origem da referida indústria e seu processo de formação e transformação. Os fatores que condicionaram a implantação da indústria de confecção na Mesoregion Sudoeste, sua escala geográfica de comercialização e suas perspectivas, foram analisadas na quarta seção. As considerações finais, são apresentadas na quinta e última seção.

\section{COMPETITIVIDADE SISTÊMICA: CONCEITOS E MODELOS}

Desde a reestruturação produtiva, nas décadas de 70 e 80 , o tema da competitividade tornou-se bastante freqüente no debate econômico. Com as transformações econômicas dos anos 80 e 90, a partir da globalização econômica, paulatinamente, a tradicional visão de competitividade foi suplantada à medida que foram ampliando-se os elementos constitutivos da capacidade de competir das nações.

Na concepção de Porter (1989, p. 6), a idéia de nação competitiva é insuficiente para explicar de forma irrefutável tanto a prosperidade do país como de suas empresas. Para o autor, deve-se abandonar toda a idéia de nação competitiva, pois afinal a principal meta de um país é produzir um padrão de vida elevado e ascendente para os seus cidadãos e a capacidade de produzir isso não depende da idéia de competitividade, mas sim da produtividade ${ }^{2}$ com a qual os recursos nacionais (trabaIho e capital) são empregados. Por ser a causa principal da renda per capita, a produtividade é o determinante principal do padrão de vida de um país.

O único conceito significativo de competitividade a nível nacional é a produtividade nacional. Um padrão de vida em elevação depende da capacidade das indústrias do país de atingir altos níveis de produtividade e aumentála, com o tempo. (PORTER, 1989, p. 6)

2 A produtividade, segundo Porter (1989), é o valor do que é produzido por uma unidade de trabalho ou de capital. 
MIGLIORINI, S. M. S. A implantação e a consolidação da indústria de confecção...

Para o referido autor, a produtividade elevada, além de sustentar níveis elevados de renda, cria a renda nacional que é tributada para custear os serviços públicos, consequentemente melhorando o padrão de vida da população, segurança, saúde, educação e mais igualdade de oportunidade.

Segundo Porter (1989, p.48/49), há duas estratégias competitivas básicas para uma indústria: o enfoque de custos e a diferenciação do produto. A vantagem competitiva de qualquer uma dessas duas estratégias traduz-se em produtividade superior à dos concorrentes. De acordo com o referido autor, para que uma indústria obtenha vantagens competitivas sobre seus concorrentes é necessário oferecer um produto comparável com aos produtos de seus concorrentes, mas desempenhar as atividades com mais eficiência do que esses (menor custo) ou, então, oferecer um produto muito melhor, que crie maior valor para o comprador e assim obter preço maior (diferenciação). A vantagem competitiva está diretamente ligada à base da renda nacional. Ou seja, quando a indústria obtém boa vantagem competitiva a produtividade nacional e, consequentemente, a renda nacional cresce.
Além dos esforços individuais de cada indústria para obter um produto competitivo no mercado, há ainda outros fatores que influenciam seu sucesso ou fracasso nessa busca. Aí entram os fatores locacionais e a influência exercida pelo meio sobre as indústrias, que são tão importantes na busca da vantagem competitiva quanto os esforços individuais de cada indústria.

Porter (1998), após ter sistematizado os estudos de várias indústrias de dez nações diferentes, classificou quatro atributos que, individualmente ou como um sistema, constituem o diamante ${ }^{3}$ da vantagem competitiva de uma nação, e acrescentou a esses mais dois fatores que afetam a competitividade das indústrias, tanto de forma negativa quanto positivamente: o papel do acaso e o papel do governo, conforme a Figura 1. Segundo o próprio autor, esses atributos podem ser facilmente aplicados em unidades políticas ou geográficas menores que um país, como um estado, região ou uma cidade.

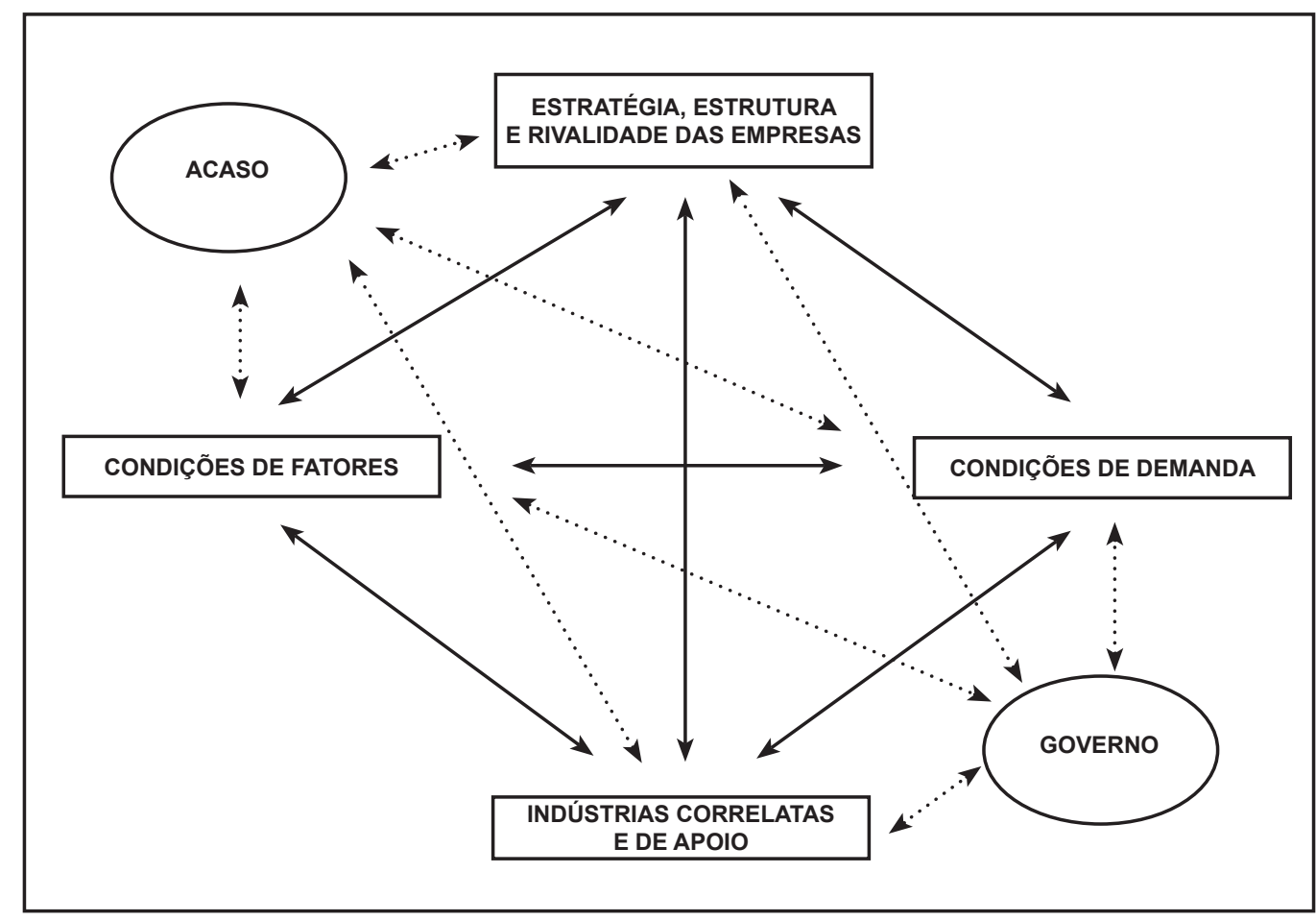

FIGURA 1 - DETERMINANTES DA VANTAGEM NACIONAL: O SISTEMA COMPLETO

FONTE: PORTER, 1989, p.146.

3 “Diamante" é a expressão usada por Porter para referir-se aos determinantes como um sistema (1989, p.88). 
MIGLIORINI, S. M. S. A implantação e a consolidação da indústria de confecção...

Nota: As setas com linhas pontilhadas representam a influencia de um fator sobre o outro nem sempre explícita, mas nem por isso deixa de ser relevante no desempenho competitivo das indústrias.

a) Condições de Fatores - são os insumos necessários para a indústria competir. Engloba desde infra-estruturas básicas como transporte, energia, telecomunicações, assistência médica, incluindo, ainda, disponibilidade de casa, instituições culturais e os atrativos de um país que afetam a qualidade de vida, passando pela oferta de mão-de-obra habilitada; abundância, qualidade, disponibilidade e acessibilidade dos recursos naturais; abarcando, ainda, os centros de pesquisas universitários e os recursos de capital que se resumem na capacidade econômica e garantias que um país dispõe para o financiamento e investimento nas indústrias.

b) Condições de Demanda - determina a natureza da demanda interna para os produtos e serviços de um país. Ou seja, determina o rumo e o caráter de melhoria e inovação pelas indústrias. Nesse determinante há três atributos gerais significativos: composição da demanda interna - natureza das necessidades do comprador - tamanho e padrão de crescimento e mecanismos pelos quais a preferência interna é transmitida aos mercados estrangeiros.

c) Indústrias Correlatas e de Apoio - referese à presença, no país, de indústrias fornecedoras e de apoio ${ }^{4}$ que sejam internacionalmente competitivas; estas podem proporcionar insumos mais eficazes em termos de custos e de modo rápido, antecipado e até preferencial. Nesse atributo, a vantagem competitiva surge da estreita relação entre os fornecedores mundialmente competitivos e a indústria.

d) Estratégia, Estrutura e Rivalidade das Empresas - é o contexto no qual as firmas são criadas dentro de um país como: condições econômicas, institucionais, culturais e jurídicas de um país bem como a rivalidade das empresas. Os rivais locais pressionam-se mutuamente para melhorar a qualidade dos produtos e serviços, reduzir custos, criar novos produtos e processos.
Já ao acaso são atribuídos aqueles acontecimentos puramente casuais, fortuitos, que pouco têm a ver com as circunstâncias de um país e que, em grande parte, estão fora do alcance das indústrias e até do governo nacional, mas que podem prejudicar ou beneficiar o desempenho das indústrias, tais como as decisões políticas de governos estrangeiros, guerras, rupturas tecnológicas - biotecnologia, microeletrônicas -, significativas mudanças nas taxas de câmbio, choque do petróleo.

Ao governo, na concepção de Porter, cabe o papel de influenciar os quatros determinantes, através das políticas nacionais. O governo pode influenciar e ser influenciado por cada um dos quatro determinantes, positiva ou negativamente: as condições de fatores são afetadas por meio de subsídios, políticas para o mercado de capital, políticas educacionais, conhecimentos científicos básicos e informações econômicas ou infra-estrutura; sobre as condições de demanda, as políticas governamentais têm-se centralizado tradicionalmente na influência sobre a quantidade geral de demanda interna, através do dispêndio governamental, ou na manipulação da disponibilidade ou custo de crédito. $\mathrm{O}$ efeito mais direto do governo sobre as condições de demanda é através da sua atuação como comprador de mercadorias e serviços. Já as indústrias correlatas e de apoio são beneficiadas através das mesmas políticas governamentais que fortalecem a vantagem competitiva das indústrias em geral. A política governamental também influi na estrutura da estratégia das indústrias e na rivalidade através de recursos como regulamentação do mercado de capital, política fiscal e leis antitrustes.

A política nacional, de acordo com o referido autor, também pode ser influenciada pelos determinantes como, por exemplo, as escolhas sobre a destinação dos investimentos educacionais, que são afetadas pelo número de competidores locais; uma forte demanda interna de um produto pode levar o governo a adotar medidas imediatas de padrões de segurança.

4 Porter define indústrias de apoio como "aquelas em que empresas podem partilhar atividades na cadeia de valores através das indústrias (por exemplo, canais de distribuição, desenvolvimento de tecnologia) ou transferir conhecimentos protegidos pelo direito de propriedade de uma indústria para outra" (1989, p.150). 
MIGLIORINI, S. M. S. A implantação e a consolidação da indústria de confecção...

Na concepção de Porter, o papel do governo é bastante limitado em sua contribuição para criar vantagem competitiva. Para o autor, embora o governo tenha importante influência sobre a vantagem competitiva nacional, seu papel é parcial. "A política governamental falhará se continuar sendo a única fonte de vantagem competitiva nacional. As políticas bem-sucedidas funcionam nas indústrias onde os determinantes subjacentes da vantagem nacional estão presentes e onde o governo os reforça" (1989, p.148). Dessa forma, cabe ao governo apressar ou aumentar as probabilidades de obter vantagem competitiva, mas ele não possui o poder de criá-la.

Uma segunda abordagem sobre a competitividade sistêmica foi realizada pelo Instituto de Desenvolvimento Alemão (IDA). O principal objetivo do desenvolvimento da competitividade sistêmica, para Esser et al. (1996), é eliminar a fragmentação social e melhorar a capacidade de aprendizagem.

O conceito de competitividade sistêmica tenta capturar tanto os determinantes políticos quanto os determinantes econômicos do desenvolvimento industrial bem-sucedido. Refere-se a um padrão em que o Estado e os atores sociais deliberadamente criam as condições necessárias para o desenvolvimento industrial bem-sucedido, sob a forma da competitividade sistêmica. (ALTENBURG et al., 1997 p.1 apud BANDEIRA, 1999).

Esser et al. (1994, p.08), por sua vez, propõe um modelo de competitividade sistêmica articulado em quatro níveis: meta, macro, meso e micro. Cada determinante da competitividade do modelo desenvolvido no IDA possui uma contribuição para o desenvolvimento da competitividade sistêmica, no entanto, nesse modelo, pode-se perceber que as políticas econômicas atuam em quase todos os níveis de determinantes da competitividade.

Nível Meta - este nível deve levar à solução conjunta de problemas. Compreende a capacidade social de organização e integração, criando consenso social da necessidade de políticas econômicas que estejam voltadas aos mercados mundiais. Também contempla as estruturas básicas de organização jurídicas, políticas e econômicas. Para Esser et al. (1994,05), criar e coordenar um padrão de organização social no espaço meta, baseado em articulação e diálogo, tem por finalidade gerar, apoiar e manter o espaço meso.

Nível Macro - o nível macro tem por objetivo assegurar condições macroeconômicas estáveis, como políticas cambiais, fiscais, orçamentárias, monetárias, políticas voltadas à concorrência das empresas (que impeçam a formação de cartéis e monopólios) e políticas voltadas ao comércio externo.
Nível Meso - este determinante abrange as condições de fatores de Porter, pois corresponde às políticas específicas desenvolvidas pelo estado e pelos atores sociais para a organização do espaço onde estão localizadas as indústrias, criando um entorno capaz de fomentar o desenvolvimento delas através de políticas de infra-estrutura física, como transporte, telecomunicações, energia, políticas de incentivo à exportação, políticas educacionais para a qualificação de mão-deobra, políticas de saúde, políticas tecnológicas, políticas regionais e ambientais.

Nível Micro - corresponde à eficiência da organização dentro das indústrias. Neste nível, cristalizase uma nova best practice de produção, na qual as indústrias buscam eficiência, qualidade, flexibilidade e rapidez de reação. Incluindo, aí, a capacidade de gestão, inovação, estratégias empresariais, busca de intercâmbio de pesquisas e desenvolvimento, integração entre fornecedores, produtores e consumidores.

Para otimizar a eficiência dos níveis micro, macro e meso, conforme Esser et al. (1996,p.10), são decisivas no nível meta a capacidade do Estado conduzir e regular a economia e a existência de padrões de organização que permitam mobilizar a capacidade criativa da sociedade. Sem a formação de estrutura na sociedade inteira, a modernização da economia e o desenvolvimento da competitividade sistêmica não alcançam resultados. $\mathrm{O}$ desenvolvimento da competitividade sistêmica é um projeto de transformação social que vai mais além da simples correção dos contextos macro e microeconômicos. Sem integração social, a competitividade sistêmica é um projeto sem perspectivas.

Quando ocorre diálogo entre os principais grupos de atores sociais assegura-se a coordenação entre os quatro níveis sistêmicos. Segundo Esser et al. (1996), para fortalecer as vantagens nacionais de inovação e competitividade, os diálogos são imprescindíveis.

No Brasil, o Estudo da Competitividade da Indústria Brasileira (ECIB), desenvolvido nos anos 90, apóia-se em um conceito de competitividade sistêmica com características que se aproximam do conceito elaborado pelo IDA. O trabalho coordenado por Luciano G. Coutinho, do Instituto de Economia da UNICAMP, e João Carlos Ferraz, do Instituto de Economia Industrial da UFRJ, inclui como fator importante para a competitividade o diálogo direto entre os atores sociais: empresários, trabalhadores, autoridades governamentais, acadêmicos e servidores públicos.

Para Coutinho e Ferraz, "a competitividade pode ser vista como a produtividade das empresas ligadas à capacidade dos governos, ao comportamento da sociedade e aos recursos naturais e construídos, e aferidos 
MIGLIORINI, S. M. S. A implantação e a consolidação da indústria de confecção...

por indicadores nacionais e internacionais, permitindo conquistar e assegurar fatias do mercado" (1993, p.11). Os determinantes da competitividade sistêmica foram subdivididos, no ECIB, em três grupos, conforme mostra a Figura 4 .

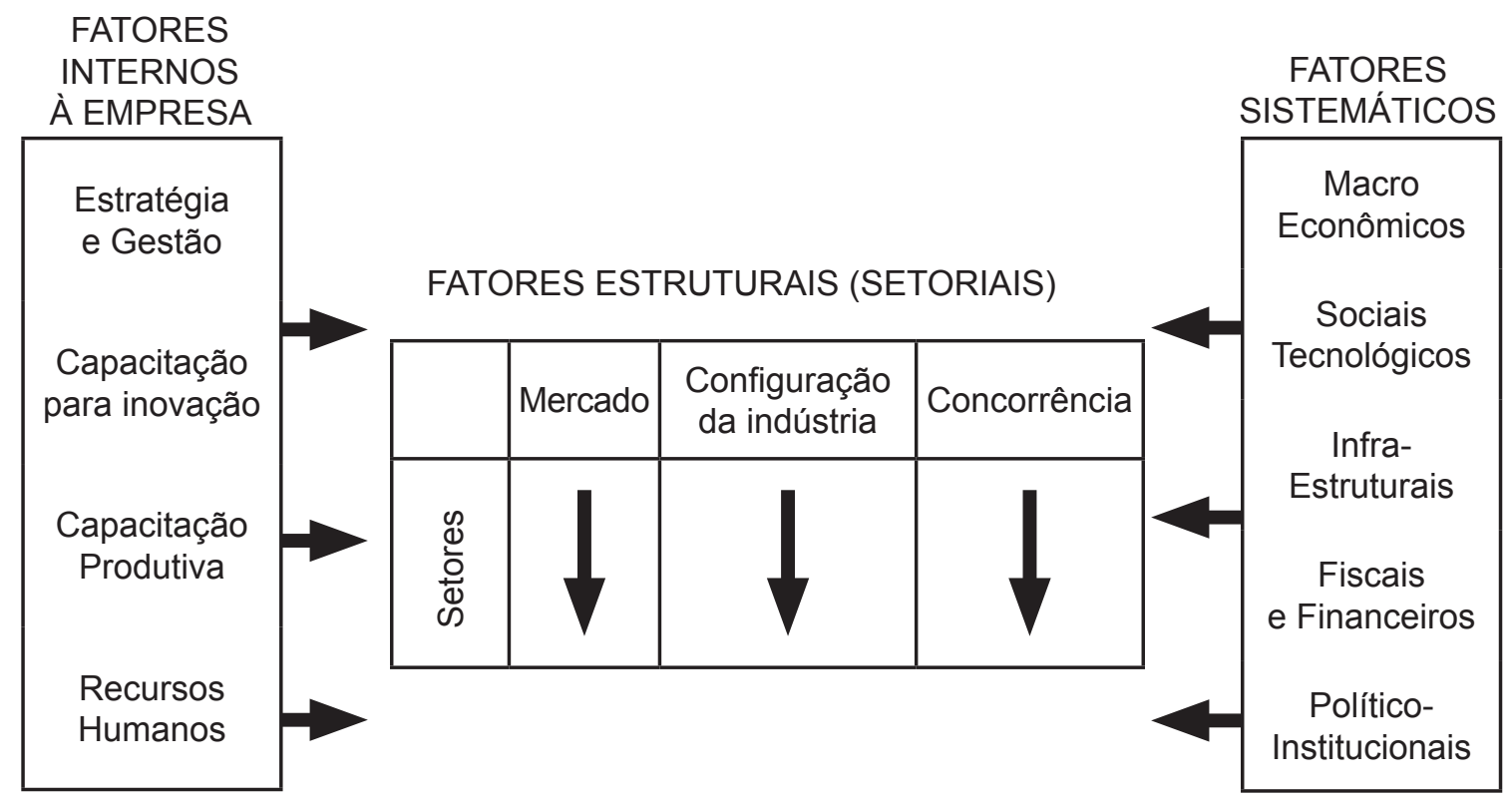

FIGURA 4 - FATORES DETERMINANTES DA COMPETITIVIDADE DA INDÚSTRIA (EMPRESA OU NAÇÃO)

FONTE: Coutinho e Ferraz, 1993, p. 21.

Fatores Internos à Empresa - são fatores que estão sob as decisões das empresas ou indústrias, equivalendo ao nível micro do sistema IDA. Através da eficiência administrativa, as indústrias diferenciam-se de seus competidores e criam vantagens competitivas.

Fatores Estruturais - são aqueles fatores que, mesmo não sendo totalmente controlados pela indústria, estão parcialmente sob a sua área de influência e definem o ambiente competitivo enfrentado pelas indústrias. Esse atributo engloba as características dos mercados consumidores referente à distribuição geográfica, às faixas de renda, oportunidades de acesso aos mercados internacionais; à configuração da indústria, como grau de concentração, escala de operação, atributos dos insumos, potencialidade de alianças com fornecedores, usuários e concorrentes, origem e direção do progresso técnico; a natureza da concorrência, meio ambiente e competidores, sistema fiscal-tributário, práticas de importação e exportação.

Fatores Sistêmicos - correspondem aos fatores externos às indústrias, mas também afetam as características do ambiente competitivo e podem ser relevantes nas vantagens competitivas que as indústrias de um país possuem ou deixam de possuir em relações às suas rivais na competição internacional. Esses fatores podem ser de natureza: macroeconômicas; políticoinstitucionais; regulatórios; infra-estrutura; sociais; fatores referentes à dimensão regional (que engloba os aspectos relativos à distribuição espacial da produção); e, por fim, fatores de escala internacional.

De uma maneira geral, a diferença fundamental entre os três modelos está na maneira de conceber as políticas públicas como um dos fatores determinantes para a competitividade das indústrias ou não. O modelo do IDA e o modelo do ECIB dão ênfase maior às políticas públicas como determinantes das vantagens das indústrias do que o modelo de competitividade desenvolvido por Porter, o qual restringe o papel do governo apenas a influenciar os quatro atributos que determinam a competitividade em seu modelo. Os três modelos de competitividades sistêmica aqui apresentados compreendem a competitividade como resultado da atuação conjunta de forças de mercado e forças que não estão relacionadas ao mercado e estão fora do alcance das indústrias, mas mesmo assim são fundamentais para o sucesso competitivo destas.

Diante do exposto, pode-se afirmar que o estudo dos fatores de competitividade sistêmica é de grande importância para avaliar o potencial de crescimento econômico de uma indústria, região ou nação. A análise 
MIGLIORINI, S. M. S. A implantação e a consolidação da indústria de confecção...

de seu conjunto de fatores, nos mais diferentes níveis, permite que se avaliem todos os aspectos relevantes para o desenvolvimento econômico das nações através de suas indústrias, podendo-se, também, identificar os pontos fortes e fracos de determinado setor econômico ou mesmo de uma região, o que pode auxiliar no desenvolvimento de políticas públicas e estratégias empresariais para o fortalecimento econômico, em escala regional, nacional ou internacional. Desta forma, como afirmam Diniz Filho e Vicentini, "o conceito de competitividade sistêmica apresenta necessariamente uma dimensão geográfica, na medida em que trata das inter-relações entre inúmeros fatores de produção que possuem expressão espacial e que ocorre em escalas variadas, que vão do regional ao global" (2004, p. 113). Dessa forma, o conceito de competitividade sistêmica, por agrupar os fatores competitivos em diferentes níveis, será de grande importância para identificar, na Mesoregion Sudoeste, os fatores que condicionaram a implantação e o desenvolvimento da indústria de confecções bem como sua competitividade atual. Na próxima seção, analisa-se a competitividade da indústria de confecção nacional, a partir do modelo de competitividade sistêmica desenvolvida por Coutinho e Ferraz para o Estudo da Competitividade da Indústria Brasileira.

\section{COMPETITIVIDADE DA INDÚSTRIA DE CONFECÇÃO BRASILEIRA}

A indústria de confecção ${ }^{5}$ brasileira não difere das outras indústrias quanto aos fatores condicionantes de competitividade. Para levantar os fatores determinantes da competitividade do complexo têxtil e, consequentemente da indústria de confecção, Coutinho e Ferraz seguiram o modelo desenvolvido para o estudo da competitividade da indústria brasileira como um todo, o qual está subdividido em três grupos de condicionantes: fatores internos à empresa; fatores de natureza estrutural - pertinentes aos setores e complexos industriais - e fatores de natureza sistêmica.
Nos fatores internos à empresa, ou fatores empresariais, o Estudo da Competitividade da Indústria Brasileira (ECIB), coordenado por Coutinho e Ferraz (1993a e 1993b), constatou que a indústria de confecção brasileira possuía uma fraca adoção de estratégias empresariais e de capacitação tecnológica e gerencial. Praticamente inexistiam processos de integração e cooperação entre as indústrias; havia grande disparidade tecnológica entre elas; a utilização de técnicas organizacionais modernas ainda era restrita no setor, sendo poucas as indústrias que utilizam técnicas de organização como círculos de controle de qualidade, just-in-time - que tem como princípio o melhor aproveitamento possível do tempo de produção -, Kanban - controla a reposição de estoques por meio de senhas -, e Grupos de trabalhos, que tendem a melhorar o ambiente de trabalho; o treinamento da mão-de-obra era uma prática pouca utilizada na indústria.

Nos fatores estruturais, o estudo do ECIB (1993a, p.44/45) apontou a heterogeneidade da indústria de confecção como responsável pelos diferentes desempenhos e inserções competitivas. Apenas poucas indústrias conseguiram reunir as capacitações necessárias para uma penetração competitiva no mercado internacional, e essas são, em geral, grandes indústrias com boa atualização tecnológica e organizacional. A subcontratação de indústrias menores para a prestação de serviços, ou seja, a terceirização de algumas fases da produção ou mesmo a subcontratação total de certas linhas de produtos, era, no início da década de 1990, uma das principais estratégias competitivas desse setor. No Brasil, essa prática tem visado apenas à redução de custos diretos, sem maior preocupação com a qualidade do produto e, na maioria das vezes, visa, principalmente, contornar obrigações tributárias e trabalhistas. Também havia uma tendência à concentração geográfica da indústria em uma mesma região, o que pode servir para estreitar relações interindústrias e estimular a cooperação, como é o caso dos pólos de Vilar dos Teles (RJ) e o pólo de Americana (SP). 
MIGLIORINI, S. M. S. A implantação e a consolidação da indústria de confecção...

Entre os fatores sistêmicos que dificultavam o aumento da competitividade da indústria de confecção, no início da década de 1990, conforme o estudo do ECIB (1993a, p.46 e 1993b, p.40), encontrava-se a ausência de crescimento da renda nacional, uma vez que a produção era voltada fundamentalmente para mercado interno. Em vista da crescente intensidade de capital, a restrição à disponibilidade de crédito para as pequenas e médias indústrias a médio e longo prazo bem como seu custo são fatores desfavoráveis à competitividade do setor. Esse fator tende a acentuar a concentração da produção e a heterogeneidade tecnológica.

Outro fator importante, que contribuía (e ainda contribui) negativamente para o aumento da competitividade do setor, é o sistema tributário, com sua complexidade e abrangência. "Os impostos em cascata elevam os custos dos insumos, bens de capital e do produto final sem a oportunidade de serem desonerados nas exportações" (Idem, 1993b, p.47). A "guerra fiscal" entre as Unidades da Federação também se constitui num condicionante negativo para o aumento da competitividade do setor de confecção. Essa prática - que pode ser tanto a isenção do ICMS como a permissão para pagamento desses benefícios a prazos dilatados e sem correção dos débitos fiscais - introduz distorções ao incentivar relocalização industrial em condições de tratamento tributário instáveis.

A alta carga tributária sobre os encargos sociais é outro fator que desfavorece a competitividade do setor de confecção nacional, intensivo em mão-de-obra. Conforme dados da ABRAVEST (2006, p.06), chega a 117\% do valor da folha de pagamento, sendo o percentual mais elevado entre os países produtores de confecção. Esse fator contribui sobremaneira para a estratégia de terceirização, ou informalização, adotado pela indústria nacional que, além de manter parcela importante da força de trabalho sem cobertura das obrigações sociais, estabelece uma concorrência predatória com as indústrias do setor formal. Indústrias que cumprem as obrigações sociais não conseguem competir em preços com as indústrias que atuam de modo informal, tornando quase que inevitável a participação daquelas no processo de informalização.

Em relação à questão internacional, o estudo do ECIB considera como principais fatores de competitividade sistêmica a proteção tarifária, condições de acesso aos principais mercados e o Mercosul.

O complexo têxtil, em 1990, foi o primeiro setor produtivo a antecipar a abertura comercial, alegando a ameaça ao plano antiinflacionário alimentado por itens de vestuário. Esse processo que liberalizou as importações não teve acompanhamento de mecanismos eficazes como apoio à capacitação tecnológica e redução da carga tributária para que as indústrias brasileiras conseguissem competir de igual para igual com as indústrias estrangeiras. Segundo o SEBRAE (2006), os juros elevados, o câmbio defasado e os impostos somaram uma contra-força que desalinhou a competitividade da indústria de confecção em relação à concorrência internacional.

No entanto, a abertura de mercado com redução de alíquotas para importação de confeccionados, conforme a ABRAVEST (2006, p.08), em alguns aspectos, foi considerado útil ao setor, levando-o ao seu reposicionamento de forma a competir com os concorrentes internacionais.

A abertura econômica do início dos anos de 1990, que provocou grande aumento das importações de produtos de confecções vindos da China e da Índia, principalmente, após meados da década, quando ocorreu o fortalecimento da moeda nacional, fez com que a indústria de confecção nacional passasse por forte reestruturação. Boa parte das indústrias que conseguiram sobreviver à abertura econômica passou por uma modernização. Segundo a Federação das Indústrias do Estado de Minas Gerais - FIEMG - (2006, p.01), atualmente, as indústrias de confecção brasileiras passaram a investir mais em tecnologia, mão-de-obra qualificada, e aumento de produtividade, favorecendo a competição no mercado nacional e internacional.

Outro fator relevante para a competitividade da indústria nacional, conforme a FIEMG (2006, p.01), está na utilização de novas matérias-primas. O Brasil passou a ter acesso, com a abertura do mercado, aos mercados internacionais que fabricam tecidos modernos a preços competitivos. Além disso, segundo ABRAVEST (2006, p.11), na fase de desenho e corte grandes avanços foram obtidos com a introdução da tecnologia CAD/CAM, permitindo a economia de tecidos e ganhos de velocidades nas etapas de criação, especificação técnica das peças e modelagem. A subcontratação ou a terceirização da produção nas fases de costura e montagem das peças, segundo a referida fonte, ainda continuam sendo usadas como estratégia empresarial pelas indústrias nacionais, visando principalmente contornar obrigações sociais, ou seja, essa estratégia vem sendo confundida no Brasil com informalização da mão-de-obra para diminuir custos.

A criação de marcas próprias e a formação de pólos regionais, segundo a ABRAVEST (2006, p.11), atualmente, vêm sendo adotadas como estratégias empresariais para aumentar a competitividade da indústria nacional frente aos seus competidores nacionais e internacionais. Do mesmo modo, vem ocorrendo no Brasil uma relocalização espacial da indústria para regiões que ofereçam mão-de-obra abundante e de menor custo, carga tributária mais baixa e incentivos fiscais. 
MIGLIORINI, S. M. S. A implantação e a consolidação da indústria de confecção...

Devido a essas estratégias e à modernização de boa parte das indústrias nacionais, segundo a FIEMG (2006, p.02), algumas indústrias passaram a exportar parte de sua produção.

Diante disso, pode-se dizer que, após o setor de confecção nacional ter enfrentado uma grave crise com a abertura da economia, medidas mais consistentes vêm sendo adotadas na tentativa de melhorar a competitividade da indústria em relação aos produtos internacionais. Afinal, cada vez mais vem ocorrendo a eliminação das barreiras mercantis entre os países, tornando os mercados mais globalizados. Nesse contexto, está a eliminação do Acordo Multifibras6 - MFA (na sigla em inglês), um dos principais acordos internacionais sobre a comercialização de têxteis e vestuários, que vigorava desde 1974, e a Rodada de negociações internacionais sobre tarifas e comércio ocorrida no Uruguai em 1994 - chamado de Rodada Uruguai, quando o Acordo começou a ser adaptado às regras do GATT (Acordo Geral sobre Tarifas e Comércio). O texto final da Rodada Uruguai determinou a eliminação gradativa de todas as cotas do MFA e de outras cotas referentes a produtos têxteis. Passou a vigorar um novo acordo, o Acordo de Têxteis e Vestuário (ATV), que pode ser considerado um acordo de transição, com um período de vigência limitado. Conforme Prochnik (2002, p.14), o novo ATV objetivava liberalizar o comércio do setor têxtil e confecção em dez anos, entre 1995 a 2005. Nesse período, as regras do antigo Acordo Multifibras, conforme o referido autor, foram gradualmente desmanteladas, eliminando as restrições quantitativas impostas aos produtos. Assim, esse novo Acordo reduziu, gradualmente, a quantidade de produtos que estão sujeitos às restrições e aumentou o tamanho das cotas de importações. Dessa forma, os produtos, gradativamente, foram deixando de ter sua comercialização regulada pelo ATV e passaram a ser submetidos às regras da Organização Mundial do Comércio - OMC.

\section{IMPLANTAÇÃO E DESENVOLVIMENTO DA INDÚSTRIA DE CONFECÇÃO NA MESOREGION SUDOESTE DO PARANÁ}

A indústria de confecção é um dos setores industriais mais antigos do Brasil. Essa indústria, juntamente com o setor têxtil, segundo Furtado (1988, p.208), foram os setores precursores da industrialização brasileira e estiveram na liderança do processo de industrialização do Brasil, com grande importância no seu desenvolvimento econômico, tanto na produção de renda como na geração de emprego. Esse setor, conforme Brum (2000, p.215), esteve na liderança do processo de industrialização do Brasil até meados da década de 1950, quando a economia do País passou por um forte processo de modernização com a emergência de setores mais dinâmicos da economia que se posicionaram à frente nesse processo. No entanto, mesmo não estando mais na liderança, a indústria de confecção, nas décadas seguintes, continuou a se desenvolver e contribuir para o desenvolvimento da economia brasileira.

Na década de 1990, conforme Oliveira (1996, apud PEREIRA et al., s/d, p.03), com a abertura da economia ao mercado externo, o crescimento das importações de produtos e confeccionados alcançou patamares bastante elevado, chegando a mais de $200 \%$ entre 1993 e 1995. Os produtos importados chineses e coreanos, conforme o referido autor, chegaram ao mercado brasileiro a preços bem menores que os da indústria nacional, causando a falência de centenas de indústrias e o encerramento de milhares de postos de trabalho.

A crise intensificou o "espraiamento" regional da indústria de confecção sobrevivente à ela, antes fortemente concentrada na região Sudeste do País. Algumas regiões que ofereciam maiores vantagens competitivas para o desenvolvimento dessas indústrias (caso da região Nordeste e parte do Estado de Minas Gerais), tiveram seu parque industrial de confecção ampliado pelo deslocamento de indústrias antes instaladas na região Sudeste do País, principalmente, enquanto outras observaram crescimento de seu setor industrial de confecção através da implantação de dezenas de novas unidades produtivas, mais adequadas ao novo contexto econômico, que vieram substituir as indústrias antigas que foram à falência com a chegada da crise ocasionada pela abertura da economia ao mercado externo e, conseqüente, crescimento das importações de confeccionados. Nesse último caso, se insere a região Sudoeste do Paraná, onde as primeiras unidades industriais de confecção foram implantadas no final da década de 1970 e início da década de 1980, mas na

6 "O Acordo Multifibras objetivava, principalmente, a contenção de exportações, através do estabelecimento de cotas e tarifas. Neste acordo, predominavam as negociações bilaterais e os países em desenvolvimento foram os mais prejudicados, pois além das restrições quantitativas, era permitido que os países desenvolvidos adotassem certas medidas de caráter extraordinário para defenderem os produtos nacionais" (PROCHNIK, 2002, P.14). 
MIGLIORINI, S. M. S. A implantação e a consolidação da indústria de confecção...

qual somente a partir do início dos anos de 1990 o setor teve crescimento expressivo e territorializou-se pela maioria dos municípios, conforme Mapa 1. A indústria de confecção, por exigir pouco nível tecnológico e pequeno investimento de capital, foi uma das indústrias precursoras do processo de industrialização da região Sudoeste do Paraná e, assim como ocorreu no início da industrialização brasileira, se tornou um dos setores mais importantes para o desenvolvimento econômico da
Região. A origem da indústria de confecção na região Sudoeste vem da transformação dos alfaiates, na década de 1970 e 1980, em unidades industriais, surgindo, segundo IPARDES (2005, p.21), primeiramente nos municípios de Francisco Beltrão e Ampére. O sucesso dos primeiros empreendimentos motivou o surgimento de muitos outros que estão presentes em 25 dos 37 municípios que compõem a região Sudoeste.

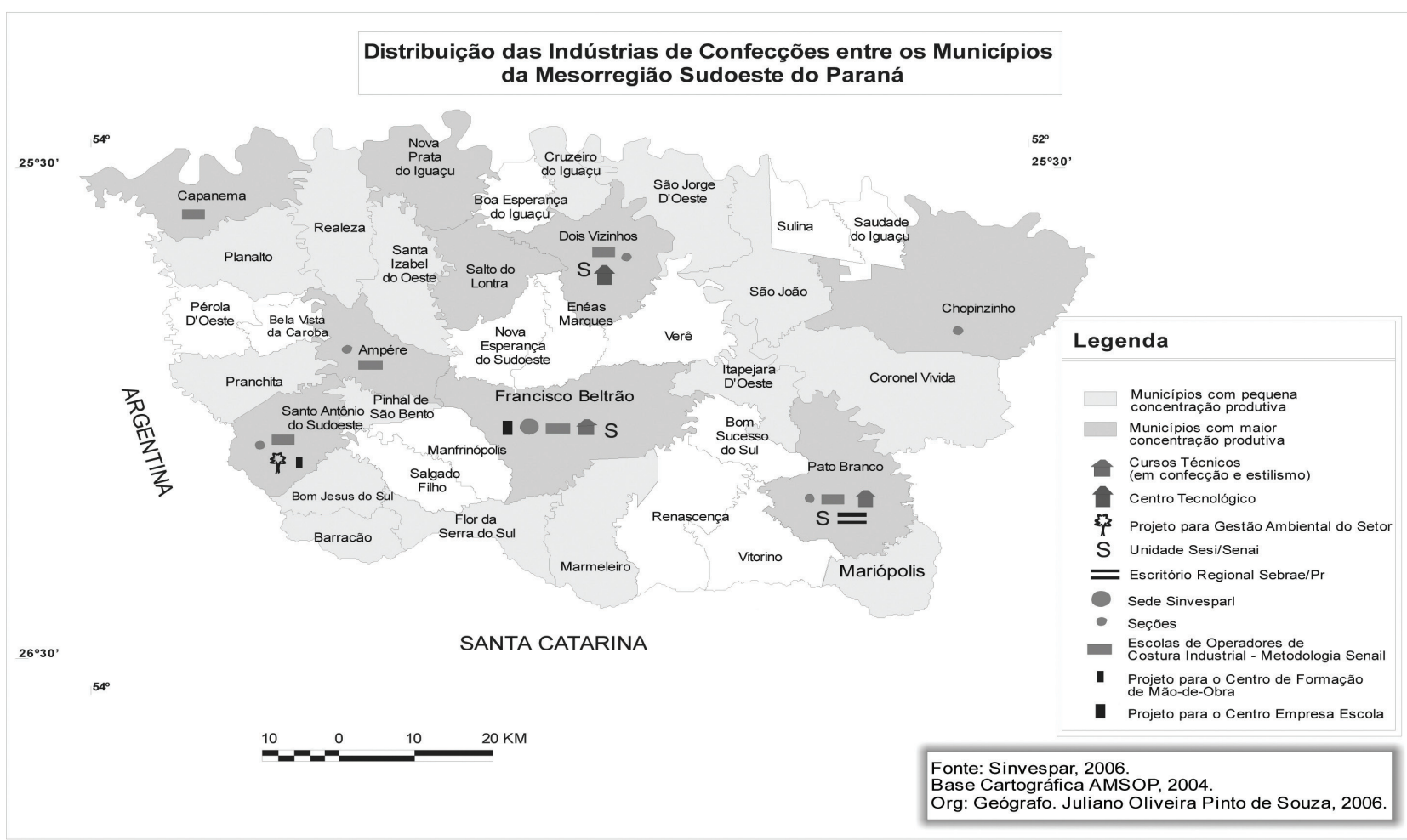

MAPA 3 - DISTRIBUIÇÃO ESPACIAL DAS INDÚSTRIAS DE CONFECÇÃO DENTRO DA MESOREGION SUDOESTE DO PARANÁ

Na década de 1990, em função da abertura da economia ao mercado externo e com isso o crescimento das importações de artigos de confecções chineses e coreanos que tomaram o mercado nacional, o setor de confecção do Sudoeste, da mesma forma que ocorreu nas outras regiões do País, passou por forte reestruturação industrial, tendo como principal conseqüência o fechamento de dezenas de unidades industriais e o encerramento de centenas de postos de trabalho.

Contraditoriamente, na região Sudoeste, esse mesmo processo que causou o encerramento das atividades de várias unidades industriais - menos eficiente ou com custos de produção mais elevados - e o declínio das atividades daquelas que conseguiram sobreviver à crise, fez com que dezenas de novas uni- dades industriais mais adequadas ao novo contexto de maior competitividade fossem surgindo na Região, pois, segundo o SINVESPAR (2005, p.02), trabalhadores que foram despedidos e que tinham algum conhecimento no setor adquiriram máquinas e equipamentos e montaram seu próprio negócio como forma de sobreviver à crise que se instalou, na época, em todo o País, levando a um expressivo crescimento do parque industrial de confecção do Sudoeste, como poderá ser constatado logo adiante.

Em 2003, conforme o SINVESPAR (2005, p.09), o setor, em parceria com diferentes instituições da Região, engajados na proposta de alavancagem do setor, uniram-se em torno da proposta de formar o Pólo da Confecção do Sudoeste do Paraná para ser reconhecido 
MIGLIORINI, S. M. S. A implantação e a consolidação da indústria de confecção...

pelo Ministério do Desenvolvimento, Indústria e Comércio Exterior (MDIC) através do Programa dos Pólos, tornar a indústria de confecção do Sudoeste reconhecida e lançar a marca "Moda Sudoeste Paraná". Como o governo mudou sua política de desenvolvimento, segundo o SINVESPAR (2005, p.09), alterando para a formação de Arranjos Produtivos Locais (APL's) ${ }^{7}$, o projeto Pólo da Confecção do Sudoeste do Paraná, em outubro de 2005, também foi alterado para APL Confecção Moda Sudoeste. O APL Confecção Moda Sudoeste priorizou ações voltadas ao mercado nacional/internacional, gestão e formação de mão-de-obra, finanças e investimentos, meio ambiente, saúde, segurança e cidadania.

Entre os anos 1990 e 2003, segundo o Diagnostico setorial da indústria de confecções do Sudoeste do Paraná (2004, p.03), o setor de confecção do Sudoeste teve um crescimento de $157 \%$, passando de 115 unidades industriais, em 1990, para 296 em 2003. EM 2006, o parque industrial de confecção da Mesoregion Sudoeste (37 municípios), segundo o SINVESPAR (2006, p.07), é composto por 378 unidades industriais, gerando aproximadamente 5.280 empregos diretos e 2.500 indiretos com uma produção estimada de 16 milhões de peças por ano, com predominância para a moda masculina (calças, camisas e paletós) e jeans. No que se refere ao porte das indústrias tem predominância as micro e pequenas, com uma participação de $93 \%$. As indústrias de médio porte correspondem a 6,5\% e de grande porte a $0,5 \%$. A distribuição das indústrias entre os municípios da Mesoregion Sudoeste pode ser observada no Mapa 3.
Segundo IPARDES (2004, p.85), o setor de confecção, em 2002, era o segundo setor industrial com maior participação no VAF da indústria regional, com $7,4 \%$ do total produzido, e, em 2003 , o segundo maior gerador de postos de trabalho com uma participação de $23,5 \%$, perdendo apenas para a agroindústria. Os municípios que se destacam em número de unidades industriais, valor agregado e geração de emprego, de acordo com IPARDES (2005, p.19), são: Ampére, ocupando a $6{ }^{a}$ posição no ranking estadual, Dois Vizinhos (8. $\left.{ }^{a}\right)$, Francisco Beltrão $\left(14 .^{a}\right)$, Santo Antonio do Sudoeste (22..$^{a}$ ) e Pato Branco, ocupando a 28. ${ }^{a}$ posição.

\section{FATORES COMPETITIVOS QUE MOTIVARAM A IMPLANTAÇÃO DA INDÚSTRIA DE CONFECÇÃO NA MESOREGION SUDOESTE DO PARANÁ}

Os fatores competitivos que motivaram a implantação da indústria de confecção na região Sudoeste, bem como as perspectivas dessa indústria para os próximos anos foram levantados a partir dos dados coletados em pesquisa de campo junto às indústrias de confecção ${ }^{8}$. O questionário de pesquisa aplicado nas indústrias foi orientado para a identificação das fontes das vantagens competitivas da indústria de confecção, com base na bibliografia disponível sobre os condicionantes da competitividade apresentada na primeira seção deste artigo.

7 Um Arranjo Produtivo Local (APL), "pode ser definido como um aglomerado de agentes econômicos, políticos e sociais que operam em atividades correlatas, localizadas em um mesmo território e que apresentam vínculos de articulação, interação, cooperação e aprendizagem. Baseia-se numa abordagem que relaciona fatores de competitividades com a localização da produção no espaço geográfico e os vínculos existentes entre as empresas, instituições de apoio e governo. Desta forma são levados em conta no APL não apenas as empresas e suas variadas formas de representação e associação, mas também outras instituições públicas e privadas voltadas à formação e treinamento de recursos humanos, pesquisa, desenvolvimento e engenharia, promoção e financiamento". (REDEAPL, 2005). Disponível em: <http://www. redeapl.pr.gov.br>. Acesso em 31/03/2006.

$8 \mathrm{~A}$ escolha das indústrias para aplicar o questionário, devido à grande quantidade de unidades industriais de confecção existentes na região (378 unidades), foi feita pelo seu porte, utilizando a classificação feita pelo Sebrae, que tem como critério o número de funcionários: segundo o Sebrae (2006), é considerada microempresa as indústrias que empregam até 19 funcionários; pequena empresa as indústrias que empregam de 20 a 99 funcionários; indústrias de médio porte ás que empregam de 100 a 499 funcionários e de grande porte as que empregam acima de 499 funcionários. Como na Mesoregion Sudoeste 0,5\% das indústrias de confecção são de grande porte e 6,5\% são de porte médio, das 378 indústrias existentes, 26 constituem o universo da pesquisa; são 02 de grande porte: uma com 520 funcionários e uma com 1.150; e 24 de porte médio. O questionário foi aplicado nas 26 unidades industriais que compõem o universo da pesquisa. 
Como já mencionado anteriormente, nos últimos anos, especialmente na década de 1990, o setor industrial de confecção da Mesoregion Sudoeste do Paraná teve forte crescimento em número de unidades industriais e os fatores que motivaram a instalação das indústrias de confecção na Mesoregion Sudoeste, tanto na década de 1990 como nas décadas anteriores e posteriores, podem ser observados na Tabela 1.

TABELA 1 - FATORES QUE MOTIVARAM A INSTALAÇÃO DAS INDÚSTRIAS DE CONFECÇÃO NA MESOREGION SUDOESTE DO PARANÁ

\begin{tabular}{|c|c|c|}
\hline FATORES & N. DE INDÚSTRIAS & $\%$ \\
\hline O Proprietário residia na região. & 21 & 51 \\
\hline Disponibilidade e custo de mão-de-obra. & 10 & 25 \\
\hline Doação de terrenos, barracão e incentivos fiscais. & 6 & 15 \\
\hline Mão-de-obra qualificada. & 2 & 5 \\
\hline Proximidade geográfica com o mercado fornecedor e consumidor. & 1 & 2 \\
\hline Não respondeu. & 1 & 2 \\
\hline Total $^{*}$ & 41 & 100 \\
\hline
\end{tabular}

FONTE: Pesquisa de Campo - 2006

* O total de respostas é superior ao número da amostra porque o empresário poderia apresentar mais de uma resposta.

O que mais pesou na escolha da Região Sudoeste para a instalação das unidades industriais de confecção foi o fato de o empresário residir na própria Região (51\%). Essa predominância, em parte, é decorrente do perfil dos empresários da Região que, quando iniciaram suas indústrias, em sua maioria, possuíam pouco capital para investir no negócio, caracterizando uma indústria familiar voltada à sobrevivência. Na década de 1990, esse fato foi ainda mais evidente: como conseqüência do encerramento de centenas de postos de trabalho devido à crise, a mão-de-obra residente na Região que detinha bom conhecimento sobre o setor montou seu próprio negócio como forma de sobrevivência.
Além disso, a disponibilidade e custo da mão-deobra e os incentivos governamentais como doação de terrenos, barracões e incentivos fiscais foram apontados por $25 \%$ e $15 \%$, respectivamente, do total das respostas (41) como fatores que influenciaram na escolha da Região para a instalação das indústrias.

Sobre as maiores vantagens competitivas que as indústrias de confecção encontram na Região Sudoeste em comparação a outras regiões do Estado ou do País, a importância dos incentivos governamentais ofertados na Região, o custo da mão-de-obra pago pelo setor e a disponibilidade de mão-de-obra apresentam-se como as principais vantagens competitivas que a Região Sudoeste oferece para o desenvolvimento da indústria de confecção, como mostra a tabela 02.

TABELA 2 - MAIORES VANTAGENS COMPETITIVAS QUE A INDÚSTRIA DE CONFECÇÃO ENCONTRA NA MESOREGION SUDOESTE EM COMPARAÇÃO A OUTRAS REGIÕES DO ESTADO OU PAÍS

\begin{tabular}{l|cc}
\hline \multicolumn{1}{c}{ VANTAGENS } & N. DE INDÚSTRIAS & \% \\
\hline Incentivos governamentais, como doação de terrenos e barracão e incentivos fiscais. & 13 & 26 \\
Mão-de-obra barata. & 10 & 20 \\
Mão-de-obra abundante. & 8 & 16 \\
Qualidade da infra-estrutura local. & 8 & 16 \\
Mão-de-obra qualificada. & 6 & 12 \\
Proximidade com o mercado fornecedor. & 1 & 2 \\
Persistência dos empresários. & 1 & 2 \\
Criatividade. & 1 & 2 \\
Não Respondeu. & 2 & $\mathbf{1}$ \\
Total* & $\mathbf{5 0}$ \\
\hline
\end{tabular}

FONTE: Pesquisa de Campo - 2006

* O total de respostas é superior ao número da amostra porque o empresário poderia apresentar mais de uma resposta. 
MIGLIORINI, S. M. S. A implantação e a consolidação da indústria de confecção...

Um em cada dois dos empresários entrevistados recebeu benefícios governamentais para a implantação de sua indústria na Região, principalmente doação de terrenos e barracões. Isso evidencia um estímulo por parte do setor público para a implantação de indústrias dessa natureza na Região. Além disso, a indústria de confecção do Sudoeste do Paraná está entre as que pagam os menores salários se comparada a outras regiões do Estado e do País?.

Os fatores oferta de mão-de-obra e mão-de-obra qualificada também foram citados pelos entrevistados como vantagem da região Sudoeste para o desenvolvimento da indústria de confecção, com um percentual $16 \%$ e $12 \%$ das respostas, respectivamente. A oferta de mão-de-obra qualificada ocorre na Região em menor nível e não privilegia todas as indústrias, fator que foi motivo de queixa de alguns entrevistados. Outro fator que está entre os mais citados pelos entrevistados, na Tabela 03, como vantagem competitiva para a indústria de confecção, na região Sudoeste, é a infra-estrutura lo- cal (transporte, energia, telecomunicação), aparecendo com um percentual de importância de $16 \%$ (08 das 50) das respostas. Em comparação com a infra-estrutura que existia na Região quando as primeiras indústrias foram implantadas, os empresários do setor reconhecem que a infra-estrutura existente, atualmente, na Região melhorou consideravelmente e em virtude de alguns dos entrevistados terem vivenciado períodos difíceis com a infra-estruturada a Região, principalmente em relação ao transporte de matéria-prima, reconhecem que esse setor teve grandes avanços.

Quanto à procedência da matéria-prima, as informações obtidas a partir dos empresários da indústria de confecção revelam um quadro de ligação da indústria de confecção da região Sudoeste com o mercado regional, nacional e internacional ${ }^{10}$; o mercado local (região Sudoeste) não tem participação no fornecimento de matéria-prima. Na Tabela 3 pode-se observar a participação dos mercados em várias escalas geográficas no fornecimento de matéria-prima para a indústria de confecção da região Sudoeste.

TABELA 3 - PROCEDÊNCIA DA MATÉRIA-PRIMA UTILIZADA PELA INDÚSTRIA DE CONFECÇÃO DA MESOREGION SUDOESTE DO PARANÁ

\begin{tabular}{l|cc}
\hline \multicolumn{1}{c|}{ PROCEDÊNCIA DA MATÉRIA-PRIMA } & N. INDÚSTRIAS & \% \\
\hline \multicolumn{1}{c}{ Região Sudeste } & 24 & 23 \\
Região Sul do País & 10 & 7 \\
Estado do Paraná & 3 & 4 \\
Outras regiões do País ${ }^{1}$ & 2 & 11 \\
Mercado internacional & 5 & $\mathbf{1 0 0}$ \\
\hline TOTAL* $^{*}$ & $\mathbf{4 4}$ & \\
\hline
\end{tabular}

FONTE: Pesquisa de Campo - 2006

* O total de respostas é superior ao número da amostra porque o empresário poderia apresentar mais de uma resposta.

${ }^{1} \mathrm{Na}$ opção "outras regiões do País" foi citada por dois entrevistados a Região Nordeste.

9 No primeiro semestre de 2006, enquanto o setor de confecção da Região Sudoeste pagava um salário de 373 reais, o salário pago pela indústria de confecção da região Oeste do Paraná, segundo o Sindicato da Indústria de Vestuário do Oeste do Paraná - SINDWEST - era de 400,89 reais, equivalendo a uma diferença de 9,3\%. Já na região Norte Central, onde se situa o APL de confecção de Maringá, o salário pago pelo setor, no mesmo período, segundo o Sindicato dos Alfaiates, Costureiras e Trabalhadores na Indústria de Confecção de Roupas de Maringá - SINCONFEMAR, era de 430 reais, ou seja, 15\% superior ao salário pago na região Sudoeste. Em relação a outros estados do País, como Santa Catarina e São Paulo, por exemplo, as diferenças salariais são ainda maiores. Em Santa Catarina, o salário pago pelo setor de confecção às costureiras, no primeiro semestre de 2006, na região de Blumenau e Brusque, segundo o Sindicato dos Trabalhadores Têxteis e Fiação de Blumenau, variava em torno 450 a 700 reais dependendo do porte da empresa. Já em São Paulo, capital, o salário pago no mesmo período, segundo o Sindicato das Costureiras de São Paulo e Osasco, era de 624,56 reais.

10 Considera-se nível local a própria região Sudoeste, regional o estado do Paraná, nacional as demais regiões do Brasil e internacional os demais países. 
MIGLIORINI, S. M. S. A implantação e a consolidação da indústria de confecção...

Das 44 respostas obtidas sobre a procedência da matéria-prima utilizada pela indústria de confecção da Região Sudoeste, 55\% apontou a região Sudeste, principalmente o estado de São Paulo, como mercado fornecedor. Das 24 unidades industriais que apontaram a região Sudeste como mercado fornecedor de sua matéria-prima, $75 \%$ adquirem dessa região de 75 a $90 \%$ da matéria-prima utilizada em sua produção e $25 \%$ adquirem de 50 a $75 \%$. Esse dado coloca a região

sudoestina, conforme mostra a Tabela 4
Sudeste como principal fornecedora de matéria-prima para a indústria de confecção da região Sudoeste do Paraná. Existem ainda 05 indústrias (11\%) que adquirem parte de sua matéria-prima no mercado internacional, cujo percentual de participação utilizada pela indústria é de até $25 \%$. A espacialização do mercado fornecedor de matéria-prima utilizada pela indústria de confecção da região Sudoeste. Quanto ao mercado consumidor das indústrias de confecção da região Sudoeste, da mesma forma que do mercado fornecedor, a região Sudeste mantém maior ligação com a indústria de confecção

TABELA 4 - MERCADO CONSUMIDOR DAS INDÚSTRIAS DE CONFECÇÃO DA MESOREGION SUDOESTE DO PARANÁ

\begin{tabular}{l|c|c}
\hline \multicolumn{1}{c}{ LOCAL DE ABRANGÊNCIA } & N. DE INDÚSTRIAS & \% \\
\hline REGIÃO SUDESTE DO PAÍS & 14 & 27 \\
Região Sul do País & 12 & 23 \\
Região Sudoeste & 8 & 15 \\
Outras regiões do País (Norte e Centro Oeste) & 7 & 13 \\
Estado do Paraná & 6 & 11 \\
Outros países & 6 & 11 \\
\hline TOTAL* & $\mathbf{5 3}$ & $\mathbf{1 0 0}$ \\
\hline
\end{tabular}

FONTE: Pesquisa de Campo - 2006

* O total de respostas é superior ao número da amostra porque o empresário poderia apresentar mais de uma resposta.

As duas regiões mais apontadas pelos entrevistados como mercado consumidor dos artigos produzidos pela indústria da região Sudoeste foi a região Sudeste, especialmente o estado de São Paulo, aparecendo com $27 \%$ das 53 respostas obtidas, e a região Sul do País, com $23 \%$ das respostas. A região Sudoeste do Paraná, ou seja, o mercado local, e o estado do Paraná, ao contrário do que ocorre com o fornecimento de matéria-prima, são importantes mercados consumidores dos artigos produzidos pela indústria da referida região, apontados por 15\% (08) e 13\% (07) das 53 respostas, respectivamente, o que representa boa ligação entre as indústrias de confecção instaladas na região Sudoeste e o mercado local e regional.

As regiões Norte e Centro Oeste também são regiões importantes na comercialização dos artigos produzidos no Sudoeste, sendo apontadas por $13 \%$ das respostas que localizaram o mercado consumidor dos artigos produzidos na Região. Além do mercado nacional, das 53 respostas obtidas, 06 (ou seja, 23\% das 26 indústrias selecionadas para amostra) aponta o mercado internacional como destino de parte de sua produção. Os países consumidores dos artigos produzidos na região Sudoeste .

No que se refere às perspectivas da indústria de confecção da região Sudoeste, foi possível observar que o fim do Acordo Multifibras e do Acordo de Têxteis e Vestuários ofuscaram as perspectivas de crescimento dessa indústria, conforme a Tabela 5, por deixar as importações mais livres com o fim das barreiras comerciais; para os entrevistados representa um maior volume de importação de artigos internacionais, principalmente vindos da China e Coréia que, em função dos baixos salários pagos pelo setor nesses países e da pequena carga tributária, produzem artigos bem mais competitivos em custos que a indústria nacional. 
MIGLIORINI, S. M. S. A implantação e a consolidação da indústria de confecção...

TABELA 5 - PERSPECTIVA DA INDÚSTRIA DE CONFECÇÃO DA MESOREGION SUDOESTE DO PARANÁ PARA OS PRÓXIMOS ANOS

\begin{tabular}{|c|c|c|}
\hline PERSPECTIVAS & N. DE INDÚSTRIAS & $\%$ \\
\hline $\begin{array}{l}\text { Retração no crescimento da indústria em função do fim do Acordo Multifibras e do Acordo de têxteis } \\
\text { e Vestuários. }\end{array}$ & 11 & 42 \\
\hline Continua tudo como está, pois não há perspectiva de grandes mudanças na política econômica. & 6 & 23 \\
\hline Será um período melhor do que os últimos anos. & 5 & 20 \\
\hline $\begin{array}{l}\text { As perspectivas são ótimas, pois as perspectivas da política econômica tanto nacional como re- } \\
\text { gional é favorável ao crescimento da indústria de confecção. }\end{array}$ & 3 & 11 \\
\hline Não respondeu. & 1 & 4 \\
\hline TOTAL & 26 & 100 \\
\hline
\end{tabular}

FONTE: Pesquisa de Campo, 2006.

Dos 26 entrevistados 11 , ou seja, $42 \%$, possuem

uma perspectiva pouco otimista sobre o futuro da indústria de confecção da região Sudoeste para os próximos anos devido à liberalização do comércio desse setor. Para eles, a perspectiva para os próximos anos é de retração no crescimento da indústria em função da entrada de maior quantidade de artigos importados no mercado nacional, o que trará dificuldades para a indústria da região colocar seus artigos no mercado. Alguns dos entrevistados afirmaram que essa dificuldade já vem ocorrendo atualmente, principalmente com os artigos básicos que são os que mais possuem volume de venda. No entanto, se há aqueles que não estão tão otimistas quanto às perspectivas dessa indústria, há também os que não vêem problemas quanto ao futuro da indústria da região: é possível perceber, pela análise dos dados acima, que, entre os entrevistados, há um número maior de empresários com boas perspectivas para o futuro da indústria de confecção da região Sudoeste (54\%) do que o número de entrevistados com perspectivas de retração do crescimento da indústria (42\%), o que representa que a maioria dos entrevistados estão apostando na política econômica a nível nacional e regional.

\section{CONSIDERAÇÕES FINAIS}

As reflexões teóricas, as informações empíricas e a articulação entre elas, sistematizadas nesta pesquisa, permitiram identificar fatores que condicionaram a implantação da indústria de confecção na Mesoregion Sudoeste assim como sua escala geográfica de comercialização, a importância atual da indústria de confecção no desenvolvimento econômico da região e as perspectivas dessa indústria para os próximos anos.

Os estudos sobre a competitividade sistêmica proporcionaram a identificação dos fatores que influenciam a competitividade da indústria de confecção nos mais diferentes níveis (meta, macro, meso e microeconômico) e, consequentemente, dos fatores que determinam a escolha do local (região) para a implantação dessa indústria. Baseada nos estudos sobre competitividade sistêmica foi possível identificar vantagens oferecidas pela região Sudoeste que impulsionam o desenvolvimento econômico local/regional, tais como: posição geográfica, oferta e qualidade da infra-estrutura básica, oferta e custo de mão-de-obra; disponibilidade de terrenos e incentivos governamentais para a implantação de indústrias. Esses fatores beneficiam não somente a indústria de confecção, mas, também, outros setores industriais que contribuem para o desenvolvimento da regional.

A indústria de confecção da região Sudoeste, que teve seu início nas décadas de 1970 e 1980, experimentou forte crescimento na década de 1990 e nos primeiros anos desse novo século. Tal crescimento Ihe conferiu destaque na economia sudoestina, passando a responder pela segunda posição entre os setores industriais que mais geram emprego e renda. O crescimento do setor de confecção na região Sudoeste, de uma forma geral, pode ser considerado um fator positivo para a economia regional. Contudo, foi possível observar durante a pesquisa que a economia industrial da região está fortemente centrada em alguns poucos segmentos, caso da indústria de confecção e da indústria alimentícia, o que pode representar risco para a economia regional, especialmente no que se refere 
a indústria de confecção, já que uma crise nesse setor pode desestabilizar a economia regional. Para a região, o melhor é diversificar sua economia, pois, se um setor estiver em crise, outros mantêm o dinamismo econômico necessário para seu desenvolvimento.

A pesquisa de campo revelou que as indústrias de confecção existentes na Região Sudoeste são indústrias domésticas que tiveram origem na própria região, através de iniciativas de empreendedores que já residiam e trabalhavam nessa Região antes de implantar sua indústria, e que, em grande parte, o fato de residirem na Região Sudoeste influenciou a escolha dessa região para a implantação de sua indústria de confecção.

Fatores que, sem dúvida, impulsionaram a implantação da indústria de confecção na região Sudoeste foram a disponibilidade de mão-de-obra existente e custo de mão-de-obra pago pelo setor que foram indicados por indústrias implantadas nos mais diferentes períodos, nas décadas de 1970, 1980, 1990 e nos anos de 2000 e 2001, como fatores que motivaram a implantação dessas indústrias na Região Sudoeste, além dos incentivos governamentais como doação de terrenos, barracões e incentivos fiscais, apontados por indústrias mais recentes. A mão-de-obra qualificada, embora em porcentagem bem menor, também foi apontada como fator que influenciou na escolha da Região Sudoeste para a implantação da indústria na Região.

Diante disso, pode-se afirmar que a indústria de confecção, pelas suas características de elevada heterogeneidade e requisitos relativamente baixos de investimento em capital e tecnologia, encontrou na Região Sudoeste condições propícias para desenvolver-se devido à disponibilidade de fatores básicos de produção ali existentes.

Quanto ao mercado consumidor, a indústria de confecção da região Sudoeste apresenta forte diversidade em sua escala geográfica de comercialização, alcançando desde a própria região até o mercado internacional. $\mathrm{Da}$ mesma forma, a aquisição de matéria-prima ocorre em várias regiões do País e até no mercado internacional. Em escala nacional, a indústria de confecção da Região Sudoeste localiza-se um pouco distante de seu mercado comercial já que a Região apresenta mais forte ligação com a região Sudeste do País, seu principal mercado tanto fornecedor quanto consumidor.

As perspectivas dos entrevistados para a indústria de confecção da Região Sudoeste para os próximos anos são, em sua maioria, positivas, apesar da insegurança de alguns entrevistados devido ao fim dos acordos comerciais sobre têxteis e vestuários. Porém, o que se observa, atualmente, é uma contínua expansão do número de unidades industriais desse setor na Região Sudoeste, assim como no crescimento das plantas industriais, o que representa uma ascensão desse setor nos últimos anos, na Região.

Observa-se, assim, que entre a indústria de confecção e a região Sudoeste há reciprocidade de trocas. Enquanto a indústria de confecção encontra na Região Sudoeste condições apropriadas para se desenvolver, a região Sudoeste é recompensada pela sua produção de renda e geração de emprego.

\section{REFERÊNCIAS}

ASSOCIAÇÃO BRASILEIRA DO VESTUÁRIO. Dados do Setor de Confecções Têxteis. São Paulo, 2006. Disponível em: <http://www.abravest.org.br>. Acesso em: 28/2/2006.

BANDEIRA, Pedro. Participação, articulação de atores sociais e desenvolvimento regional. Brasília, 1999. Disponível em: <http://www.ipea.gov.br/publicacoes>. Acesso em: $12 / 2 / 2006$

BRUM, Argemiro J. O desenvolvimento econômico brasileiro. 21. ed. Ijuí: INIJUÍ, 2000.

COUTINHO, Luciano G.; FERRAZ, João Carlos (Coord.). Estudo da competitividade da indústria brasileira: competitividade do complexo têxtil. Campinas, 1993a. Disponível em: <http:// www.mct.gov.br>. Acesso em: 22/2/2006.

Estudo da competitividade da indústria brasileira: competitividade da indústria do vestuário. Campinas, 1993. Disponível em: <http://www.mct.gov.br>. Acesso em: 22/2/2006.

Estudo da competitividade da indústria brasileira: relatório final. Campinas, 1993. Disponível em: <http://www. mct.gov.br>. Acesso em: 22/2/2006.

DINIZ FILHO, L. L.; VICENTINI, Y. Teorias espaciais contemporâneas: o conceito de competitividade sistêmica e o paradigma da sustentabilidade ambiental. Curitiba, 2004. Disponível em: <http://www.calvados.c3sl.ufpr.br>. Acesso em: 31/1/2006.

ESSER, Klaus et al. Competitividade sistêmica: competitividad internacional de las empresas y politicas requeridas. Instituto Alemán de Desarrollo. Berlin, 1994. Disponível em: <http:// www.meyer-stamer.de/1994/systemsp.html>. Acesso em: 6/2/2006.

ESSER, Klaus et al. Competitividad sistémica: nuevo desafío a las empresas y a la política. Revista de la CEPAL, Santiago, $n$. 59, p. 39-52, 1996. Disponível em: <http://www.meyer-stamer. de/1996/cepal.html>. Acesso em: 6/2/2006.

FEDERAÇÃO DAS INDÚSTRIAS DO ESTADO DE MINAS GERAIS. Panorama nacional: o vestuário no Brasil. 2006. Disponível em: <http://www.fiemg.org.br>. Acesso em: 2/7/2006. 
MIGLIORINI, S. M. S. A implantação e a consolidação da indústria de confecção...

FURTADO, Milton B. Síntese da economia brasileira. 5. ed. Rio de Janeiro: Livros Técnicos e Científicos, 1988.

INSTITUTO BRASILEIRO DE GEOGRAFIA E ESTATÍSTICA (IBGE). Classificações estatísticas: CNAE 1.0, seção D - indústria da transformação. 2006. Disponível em: <http://www. cnae.ibge.gov.br>. Acesso em: 13/1/2007.

INSTITUTO PARANAENSE DE DESENVOLVIMENTO ECONÔMICO E SOCIAL (IPARDES). Secretaria de Estado do Planejamento e Coordenação Geral. Identificação, caracterização, construção de tipologia e apoio na formulação de politicas para os Arranjos Produtivos Locais (APLs) do estado do Paraná: etapa 3 - caracterização estruturar preliminar dos APLs pré-selecionados e notas metodológicas para os estudos de caso. Curitiba, 2005.

PEREIRA, Odair J. et al. A gestão organizacional no setor têxti: limites e desafio diante dos novos paradigmas da aldeia global. Maringá. Disponível em <http://www.ead.fea.usp.br>. Acesso em: 7/3/2006.

PORTER, Michael E. A vantagem competitiva das nações. Rio de Janeiro: Campus, 1989.

PROCHNIK, Victor. Estudo da competitividade de cadeias integradas no Brasil: impactos de livre comércio: cadeia têxtil e de confecções. Campinas, 2002. Disponível em: <http://www. desevolvimento.gov.br>. Acesso em: 28/6/2006

SEBRAE. Ações e principais iniciativas de apoio à cadeia no Brasil. 2006. Disponível em: <http://www.sebrae.com.br> . Acesso em: 28/6/2006.

SINVESPAR. Arranjo produtivo local moda sudoeste do Paraná. 2005. Disponível em <http://www.sinvespar.com.br>. Acesso em: 29/3/2006.

SINVESPAR. APL moda masculina sudoeste do Paraná: plano de desenvolvimento: o arranjo produtivo local de moda masculina do sudoeste do Paraná. 2006. Disponível em: <http:// www.sinvespar.com.br>. Acesso em: 21/6/2006.

INSTITUTO PARANAENSE DE DESENVOLVIMENTO ECONÔMICO E SOCIAL (IPARDES). Leituras regionais: mesorregião geográfica sudoeste do Paraná. Curitiba, 2004a, versão completa. Disponível em: <http://www.ipardes.pr.gov. br>. Acesso em: 10/7/2005. 
MIGLIORINI, S. M. S. A implantação e a consolidação da indústria de confecção... 